\title{
Charlotte Barlow
}

\begin{abstract}
There is a growing body of literature which highlights that women follow distinct and often gendered pathways into crime. Violence, coercion and love within intimate relationships have been increasingly acknowledged as motivating factors for female offending behaviour. However, there is a lack of understanding of the ways in which emotions, such as love and fear, influence co-offending women's pathways into crime. This chapter will highlight the significance of emotions for female co-offenders, particularly when they are in an intimate, violent, exploitative and/ or controlling relationship with their partner/ co-offender. Female offenders more broadly are typically viewed to be wholly independent, rational agents or as lacking control in relation to their offending behaviour and thus having their agency completely denied. However, this dichotomy is problematic, as it fails to consider how emotional dimensions of co-offending relationships may influence offending behaviour and experiences of agency. The importance of acknowledging such emotions in social context when attempting to understand such women's offending 'choices' will be explored. Collectively, this chapter will highlight that emotions and offending behaviour are inextricably connected for female co-offenders. Such emotions need to be acknowledged and understood alongside structural factors if criminologists are to fully understand such women's motivations for offending.
\end{abstract}

\section{Introduction}

This chapter will consider the role of emotions for female co-offenders ${ }^{1}$ when offending with a male intimate partner. A high profile example of male/female co-offending in recent UK history is the case of Maxine Carr and Ian Huntley. Carr was convicted of perverting the course of justice in 2003 after she provided a false alibi for Ian Huntley on the night he murdered Holly Wells and Jessica Chapman in 2002. He was found guilty of their murder and sentenced to two life sentences, whilst Carr received a three-and-a-half year prison sentence. It was concluded during Carr's trial that she did not know that he had murdered Holly and Jessica when she provided the false alibi. Carr was represented in most news media outlets as a calculated, remorseless manipulator. However, when discussing her motivations and explanations for providing the false alibi for Huntley, she suggested that she 'lied to protect him' as she 'loved him very much' and that she also lived in fear of him, as he was abusive and controlling towards her throughout their relationship. She stated that 'no-one had any idea what kind of relationship I had with that man' (Maxine Carr's testimony, 5 and 6 December 2003). Carr's narrative suggests that her offending behaviour and initial motivation to provide the false alibi were influenced by emotions. As will be discussed throughout this chapter, emotions influence offending motivations for women co-offenders in various ways, particularly when co-offending with an abusive and controlling male co-offender/intimate partner.

Traditional criminological theories or explanations of crime have mostly left out emotion altogether. Willem de Haan and Ian Loader (2002) argued that the field of criminology needs to actively engage with the sociology of emotions if it hopes to understand the realty of criminal activity. Emotional influences on offending behaviour are significantly affected by gender. Feminist pathways research has identified that women's law-breaking is characterised by structural, institutional and familial injustices and disadvantages, the most clearly gendered of these being their frequent experience of violence and sexual victimization (Belknap and Holsinger 2006; Batchelor 2005). Due to such experiences, emotions such as fear, guilt and desperation are often influencing factors on women's participation in criminal activity and criminalisation. Coercion within intimate relationships has also increasingly been

1 The term female co-offenders will be used throughout the chapter. However, it is emphasised here that the ways in which such women are criminalised more broadly influences initial and continued 'decisions' to offend. 
acknowledged as a potential motivating factor for female offending behaviour (Barlow 2016; Jones 2008; Richie 1996). However, there is a lack of understanding of the ways in which emotions specifically, such as love and fear, influence co-offending women's initial pathways into crime and continued motivations to offend. As proposed by Gilly Sharpe (2016), it is not the intention of this chapter to identify emotions as a potential 'risk factor' for offending, as this essentialises and de-contextualises women offenders' experiences from institutional injustices. Rather this chapter aims to highlight the significance of emotions for female cooffenders, particularly when they are in an intimate and abusive relationship with their partner/co-offender, and situate their experiences within the context of the social and structural conditions and constraints which shape such women's lives.

\section{'Malestream' criminology and rationality - the absence of emotions}

What has been termed 'malestream' criminology emphasises the male-dominated nature of traditional criminological perspectives and criminology as a discipline. As highlighted by Walklate (2001: 24), early nineteenth century academics, such as Cesare Lombroso and Guglielmo Ferrero (1895), have 'framed the way in which thinking about males and females and masculinity and femininity has been constructed'. The deterministic and androcentric writings of such early criminological thinkers have had continued significance on criminological thought in more recent years. For example, in more recent history criminologists such as Albert K. Cohen and Edwin Sutherland have mostly researched men's offending and 'added women into' criminological thought, rather than researching with and about women. Gender is a key determinant of likely involvement in offending behaviour, yet the importance of gender has not always been reflected in the development of criminological thought, as such knowledge has historically been based on the assumption that crime is men's work and not women's (Walklate 2001). The late nineteenth century criminological shift from physical anthropology to the psychology and personality of offenders also evidenced clear issues with gendered understandings of offending and victimisation. The significance of emotions for women's offending began to be recognised in early psychological explanations of crime, but this was mostly framed in a damaging and derogatory manner. For example, women offenders were often viewed to be hysterical and psychologically weak in comparison to men (Russett 1989).

Emotions are regularly understood as influencing factors on desistance from crime for both men and women, with guilt and shame being recognised emotions in the restorative justice process in particular. However, there is often minimal consideration of the role of emotions on the offending act(s) itself, with explanations such as rationality and rational choice pervading criminological thought and criminal justice practice. This minimisation of emotions reinforces rationality and agency being readily ascribed to men's motivations for offending, whereas women are associated with being emotional and therefore weak-minded (Sydie 1987). Women offenders are often characterised as 'mad' in legal and media discourse, suggesting that offending motivations are implicitly linked to irrationality, hysteria or mental health issues (Ballinger 2000; Barlow 2016). Such discourse represents any emotional motivations to offend as non-agentic, and consequently represents women offenders as child-like when compared to male counterparts.

Furthermore, there is currently minimal scope for considering nuanced understandings of the influence of emotions in legal and criminal justice practice. This is due to male-defined epistemology pervading legal thought, therefore legal terminology by its nature, such as 'rational man of the law', privileges the position and perspective of men (Yeo 1993; Ballinger 2012). However, as highlighted by Anette Ballinger (2012: 452) 'to make assumptions about the population as a whole based on such constructions is to privilege the understanding of the 
world of the group which has dominated legal and public life: white, middle-class, heterosexual men'. This legal and public domination of the male perspective has led to all experiences and behaviour which falls outside these parameters to be 'othered' and consequently silenced (Barlow 2016; Ballinger 2012; Carline 2005). Ballinger (2012: 452) argues that such principles lead to a double exclusion of the female experience, due to both the gendered nature of the law and men's experiences being viewed to be hierarchically more valuable. Consequently, women's experiences are 'othered' in criminological and legal thought due to both their sex and the gendered emphasis on rationality or choice being the principle motivation for offending.

However, such male-defined explanations for offending do not reflect the experiences of many female offenders, particularly those who co-offend with a male partner. The relatively small body of research exploring women's co-offending has suggested that women often engage in more serious offending with a male partner than when they do so alone (Mullins and Wright 2003; Koons-Witt and Schram 2003), and that they are more likely to engage in gender atypical offences when they co-offend with a man, such as robbery and murder (Becker and McCorkel 2011). Scholars have also focused specifically on the experiences of women who are in an intimate relationship with their male co-offender. For example, Dorinda Welle and Gregory Falkin (2000) have suggested that these women often experience 'relationship policing', which involves many aspects of their relationship and life, including participation in criminal activity, being controlled by their romantic co-offender. The intersecting inequalities of race and gender have also been considered in relation to co-offending women's experiences. Beth E. Richie (1996: 133) has argued that an intersection of gender and racial inequality can lead women to be 'compelled' into a variety of criminal and deviant behaviours, with the notion of 'gender entrapment' helping 'to show how some women are forced or coerced into crime by their culturally expected gender roles, the violence in their intimate relationships and their social position in the broader society'. Moreover, Stephen Jones (2008) has suggested that women who co-offend with intimate male partners can have their involvement categorised in three key ways: acting as a result of coercion, offending 'out of love', and adopting an 'equal' role in the offending. I have also explored elsewhere the notion of a 'continuum of coercion' to explain how abusive, controlling and violent relationships with male, intimate partners/co-offenders may influence women's pathways into crime and offending decision-making (Barlow 2016). This body of work collectively emphasises the significance of relationships on offending behaviour for women in particular.

Domestic abuse is increasingly acknowledged as a pathway into crime and continued motivation to offend for some women offenders (Schaffner 2007; Belknap and Holsinger 2006; Barlow 2016). For example, The Duluth Power and Control Wheel, designed as part of Domestic Abuse Prevention Programmes in the United States, acknowledges coercion into crime as a potential method of domestic abuse. Furthermore, the Corston Report (2007), which evaluated women's experiences of the criminal justice system in the United Kingdom, also emphasises the importance of understanding the ways in which women's experiences of victimisation and domestic abuse influence their offending behaviour and criminalisation. However, an unintended consequence of such work and policy is that victimisation is increasingly viewed as a criminogenic 'risk factor' for women offenders, which consequently essentialises and pathologises such women. This chapter aims to extend these arguments by considering the links between emotions, intimate relationships and offending for women cooffenders, whilst situating these discussions within the broader structural and social inequalities that such women experience.

Aspects of the analysis presented in this chapter are based on an empirical study conducted with Dr Siobhan Weare. We conducted semi-structured interviews with eight women who cooffended with a male intimate partner. The women were accessing a women's advice and 
support centre in the North West of the United Kingdom at the time of interview. Semistructured, in-depth interviews were chosen as the method of data collection as they allowed for women's narratives and subjective lived experiences to be most clearly communicated. This approach also reflected the feminist methodological and epistemological approach underpinning the project; recognising the experiences of women from their own point of view (Harding 1981.). The women had engaged in a range of relatively 'low level' offences, including theft, buying and selling drugs, drug use, and benefit fraud. The interviews were analysed using Interpretative Phenomenological Analysis (IPA). This method of analysis ensured that the women's lived experience, and how they made sense of them (Smith 2004), were centralised throughout the project. All of the women have been anonymised and provided with pseudonyms. Rather than this chapter exploring the study in significant depth, as this has been done elsewhere (Barlow and Weare, 2018), key findings will be used to develop conceptual ideas.

\section{Emotions, pathways into crime and continued motivations to offend}

Emotions are an inherent aspect of intimate relationships. In abusive relationships, the victim/ survivor can experience a range of emotions, ranging from love to fear, guilt to hopelessness (Westmarland 2015; Dobash and Dobash 1979). Offending motivations and pathways into crime for women co-offenders who are in an intimate, abusive relationship with their male cooffender are therefore not separate or separable from the influence of emotions. It is recognised that many women co-offenders may not be in an abusive relationship with their male partner/ co-offender, and therefore may offend with greater levels of agency and adopt a more equal role in the co-offending behaviour. However, abuse, violence and control within a co-offending relationship were influencing factors for all of the women's offending behaviour in the current study when in a romantic relationship with their male co-offender, despite such experiences not being part of the selection criteria to be part of the study. With this in mind, although various emotions could influence women co-offenders offending motivations, fear and love will be considered at length here.

Fear is under-theorised in the discipline of criminology. As a result of patriarchy and high levels of violence against women in society more broadly, pathways into crime and offending motivations for women are likely to be influenced by fear. This is particularly the case if women co-offenders are in an abusive, violent relationship with their male co-offender/intimate partner. Such abuse can be physical, psychological, emotional and controlling in nature (Barlow 2016; Richie 1996). All of the women in our study experienced violence and abuse in their relationship with their male co-offender/intimate partner. All of these women also identified this abuse as an influencing factor on their offending behaviour. For example, Danielle stated that 'I just did whatever he told me to do. I was scared of him'. She referenced this in relation to her ex-partner pressuring her to smuggle drugs into prison whilst he was serving a prison sentence. Sarah echoed similar sentiments when discussing the reasons why she began and continued to co-offend with her intimate partner: 'He knocked the life out of me. I didn't know who I was. I was just this little coward girl who did as he asked'. Three of the women also suggested that their partners were 'controlling' and 'manipulative' throughout their relationship. They suggested that this control often limited their 'offending choices', as their male co-offender exerted control over most if not all aspects of their lives.

For six women, their intimate, abusive relationships were clearly a catalyst for their offending. For example, both Rachel and Laura stated that they 'hadn't offended before' they met their romantic co-offender. Danielle also referenced that she 'wouldn't have offended if she hadn't have met him (her ex-partner)'. For these women, the relationships with their male co-offenders seemed to form the basis for their pathways into crime. It is therefore important to acknowledge 
the potential coercive context of such women's offending. Welle and Falkin (2000) argue that women co-offenders may become involved in crime due to their fear of disappointing, angering, or disobeying their partner, highlighting the influence of fear on such women's offending 'choices'. The sustained and insidious nature of such coercive and abusive relationships mean that control can be exerted with or without the presence of the perpetrator, controlling such women's space for action (Kelly 2003; Stark 2007).

Jones (2011) also notes that male co-offenders often pressure women to take the blame for offences committed on their behalf. This was particularly relevant to Rachel's circumstances in our study. Rachel explained how her ex-partner 'threatened suicide' every time she tried to leave the relationship, evidencing his control and manipulation. She also discussed how he pressured her to commit benefit fraud, as they were struggling financially, mostly due to his gambling addiction. She suggested that even though he was the 'mastermind' behind the plan, he 'pressured' her to adopt the active role in the offending. Rachel said that 'he convinced me it was because he loved me' and it was 'always just pressure, pressure, pressure to do it'.

In such coercive circumstances, male co-offenders may also additionally exploit the social circumstances of women, particularly if they are addicted to drugs (Fleetwood 2013) or living in poverty (Carlen 1988). Three of the women in our study were addicted to drugs and highlighted a clear link between their drug-taking and relationships with their co-offenders. The specifics of the link varied for each of the women. The most extreme example was provided by Vicky who had never taken drugs before her romantic co-offender pressured her into doing so:

At first I used to say that I didn't want to do it. He offered it me all the time, used to call me a pussy for not wanting any and eventually, I just couldn't be arsed with him being on my case all the time so I did it.

Her ex-boyfriend became her drug dealer and then tricked her into taking heroin, intensifying her addiction:

It started off with just weed and stuff like that and by the end he get me into heroin and all sorts. I remember one time he told me he had given me a bag of brown (weed) and I took it as normal, he started laughing and said it was fucking heroin. Fucking heroin. That was the first time I took it and it went from there really.

This example highlights the importance of considering the broader context of such relationships when attempting to understand women co-offenders' behaviour and decision making, rather than focussing exclusively on the offending act itself. Understanding the ways in which co-offending women's abusive and exploitative relationship with their partner and in Vicky's case, addiction to drugs (or other influencing factors) may intersect to produce multiple, over-lapping offending influences leads to a more nuanced understanding of their lived experiences. Furthermore, recognising the context and influence of abusive relationships highlights the impact of emotions on such women's participation in offending. For example, after Vicky became addicted to heroin, she became dependent on her male co-offender to supply her with drugs. Consequently, he occasionally put pressure on her to take the blame for their or his offending when caught by the police in exchange for drugs, or she felt obliged to do this out of loyalty (as both her romantic partner and drug dealer). This highlights the added 
power dynamic in Vicky's relationship, due to her male co-offender being both her drug dealer and intimate partner.

However, emotions such as fear also need to be located in the structural context of such women's lives. To varying degrees, the women in our study were economically disadvantaged, experienced mental health issues, had experienced childhood victimization and abuse and engaged in substance misuse at some point in their lives. Such experiences of marginalisation need to be located within the broader context of gender inequality, adding further complex dynamics to the structural constraints the women experienced. It is within this context that the women's emotional experiences of fear, and the subsequent influence this had on their cooffending, needs to be considered. Of particular significance are state, criminal justice and other agency responses (or lack of) to the women's experiences of victimisation. As previously discussed, all of the women experienced extensive victimisation throughout their lives, yet none of them received effective (if any) criminal justice support for this. For example, the women in our study suggested there was no point in contacting the police about the abuse they had experienced within the context of their intimate relationship as they would not be believed as they thought that the police 'hated' them (Sarah). Both Sarah and Laura described their 'hatred' for the police, due to previous negative and in their view harmful interactions with them. Most of the women in our study were readily criminalised by criminal justice professionals, but their experiences of victimisation were minimised or not fully investigated. One of the women herself acknowledged the issue with subjectivity and discretion influencing the decision-making of criminal justice professionals. When reflecting on the outcome of her case and why she was not sent to prison for the crimes she committed, Lucy stated:

I think it was based on my character references, which is ridiculous. Cause if I hadn't of known local councillors, because I lived on the same street as them ... it shouldn't be like that should it? It should be based on the facts. Cause if I didn't know them, would I be in prison? Maybe ...

Policing and criminal justice practices involve judgements about riskiness and perceived identities of 'victimhood', which are cross cut by intersecting inequalities such as race and class, ultimately leading to marginalised women more readily coming into contact with the criminal justice system as offenders, rather than victims, irrespective of experiences of victimisation (Sharpe 2016; Burman and Batchelor 2009; Schaffner 2007).

Furthermore, some of the fear experienced by the women was not only as a consequence of their abusive, intimate relationship, but also due to a lack of state support and fear of punitive state response. For example, Denise reflected on her negative experience of prison, stating 'my hair went dead white. I was crying all the time, my blood pressure wouldn't go down'. She went onto say that the experience continues to affect her post-release, stating that 'if someone slams the door, I jump now. You know what I mean?' Prior to going to prison, Denise had mental health issues which she suggests were further exacerbated by the prison experience. Two of the women also reported being homeless after serving a short-term prison sentence for low level offences. One of the women appeared to be financially dependent on her male partner/co-offender and received minimal economic support from the state when released from prison. This meant that she had to make the 'choice' of returning to her abusive partner and likely continue engaging in co-offending, or being homeless. Although returning to an abusive relationship may be perceived as an agentic choice, she made such choices within the context of broader structural constraints, such as economic marginalisation. This is arguably an example of a state-sanctioned negative consequence for such women, constraining their 
capacity for autonomy and independence and rendering them at greater risk of intimate partner violence (Sharpe 2016). Additionally, as most of the women were known in some capacity to state authorities mostly due to their previous offending, some suggested that they were afraid to make social services or criminal justice practitioners aware of their experiences of victimisation, due to fear of their children being taken away from them or other negative repercussions. This therefore suggests that punitive responses and systematic failings by the state to recognise women co-offenders' experiences of victimisation added another layer of fear, which consequently influenced their offending motivations.

When conceptualising fear as an offending motivation for women co-offenders, previously discussed explanations such as rationality are clearly in conflict. This raises important questions about perceived offending 'choices' (or lack of). For the women in this study, although some recognised that they made a 'choice' to offend, others suggested they had 'no choice' (Danielle, Rachel, Laura) and all suggested that their choices were influenced by their abusive relationship with their intimate partner. This is exemplified by Vicky, stating: 'I felt like a prisoner in my relationship with him', which she believed consequently limited her perceived choices. The women's offending choices therefore need to be understood within the context of both their abusive relationships and their broader structural and social position in society. Rather than being a 'rational choice', the women arguably evaluated and drew upon the limited options available to them due to their social and structural positioning (Fleetwood 2015).

The role of the state and criminal justice organisations in exacerbating experiences of victimisation and adding to the harms such women experience is often ignored or minimised. It is argued here that the structural constraints many female co-offenders experience, combined with inadequate and harmful state responses to their experiences of victimisation, increase their feelings of fear and desperation, rather than providing empowering support. When considering the role of emotions on female co-offenders offending behaviour, the fear of their abusive partner/co-offender is therefore not separate or separable from their fear of punitive and harmful state responses and their broader social and structural position in society.

As well as fear influencing women co-offenders' motivations to offend, emotions such as love may also impact decision-making. In our study, for Vicky there was a clear overlap between fear of her partner (discussed above) and the love she felt for him. She explained how she 'would have done anything for him' but also that she believed he 'took the piss out of how much I loved him'. She referenced this in relation to an occasion when she took the blame on his behalf after being arrested for theft and shop-lifting they engaged in together. Love is particularly significant to consider in contexts when women take the blame or plead guilty to a crime they have not committed in order to protect the guilt of a male partner/co-offender. Research suggests that women are more likely to confess to crimes that they have not committed out of love or loyalty for male partners/family members (Jones 2011; Klaver, Lee and Rose 2008). As suggested by Catherine Gilligan (1982), whereas men's moral judgements are founded on ideas such as individual rights, women's moral reasoning is more based on the importance of human relationships and altruistically caring for the needs of others. This may explain how and why some women choose to protect their loved one by taking blame themselves (Jones 2011). A well-known example of a female co-offender suggesting that she took the blame in this context is Maxine Carr. Carr suggested that one of the reasons she provided the false alibi for Huntley on the night he murdered Holly Wells and Jessica Chapman was because 'she loved him (Huntley) very much' (Maxine Carr testimony, 5 and 6 December 2003). As highlighted by feminist critique, taking the blame or providing false alibis for male co-offenders 'out of love' needs to be located in a patriarchal context, particularly in relation to the gendered nature of caregiving responsibilities that commonly form the basis of women's socialisation from birth. 
However, rather than separating emotions of love and fear as motivating factors for women cooffenders, they should be viewed as part of the same continuum (Barlow 2016). In existing research as well as the women's experiences cited here, women co-offenders often report engaging in offending to avoid disappointing or angering their partner and/or due to loyalty and love. With this in mind, irrespective of whether the women committed a crime out of fear or love, the overlapping nature of such emotions should be considered. Many emotions can be present in the same relationship, therefore categorising and separating such experiences does not accurately reflect the reality of many such women's lives.

\section{Emotions and the preoccupation with 'choice'}

Developing an understanding of the ways in which emotions influence offending is central to gaining more nuanced insights into women co-offenders' experiences. In legal and criminal justice policy and practice, there is an emphasis on rational choice as being the key motivating and influencing factor on decision-making processes. For the women interviewed in this study, their choices were not based on rationality, but rather were at least to some extent influenced by their relationship with their male co-offender, their broader structural and social positioning in society, as well as fear of negative, punitive state response.

Failing to understand the ways in which emotions influence offending women's behaviour has led to a preoccupation with 'choice' as a central component of theorising and understanding such women's experiences. Such debates extend to feminist theorising, with Lisa Maher (1997) suggesting that female offenders are typically viewed to be either wholly in control of their offending behaviour or irrational and 'out of control' of their offending decision-making. However, this dichotomisation of choice and emotion is a reductionist approach, and does not apply to all female offenders, particularly those whose offending is influenced by fear and love. The binary dichotomy of agency and emotion leads to over-simplistic and limited understandings of many women co-offenders' experiences. However, as argued by Sumi Madhok et al. (2013: 3), dichotomising experiences of agency 'requires us to deny, or at least obscure, the extent to which social relations of inequality and domination continue to structure our lives'. This highlights the emphasis on individual, 'rational' choice and autonomy within existing understandings of agency and choice serve to minimise experiences of emotion and the ways in which deep-rooted, gender inequality and oppression impacts upon women's pathways into crime and offending motivations (Carlen 1988; Ballinger 2000; Sharpe 2016). Rather than focussing on simplistic binaries, such as 'agent' or 'victim', the complex ways in which experiences of choice and emotion are entwined should be better understood.

It is not the intention of this chapter to suggest that emotional influences deny the agency of women who offend, but rather to understand the ways in which emotions such as fear and love may impact upon offending motivations, particularly for women who co-offend with a male, intimate partner. The preoccupation on women's perceived 'choices' often leads to an avoidance of situating such choices in context. This consequently encourages a lack of understanding of the ways in which emotions may influence offending decision-making at both a micro (i.e. abusive, intimate relationship with co-offender) and macro (violence of the state) level. Recognising that women may have agency (albeit to varying levels), whilst simultaneously understanding the ways in which emotions may influence offending choices, enables our understanding of co-offending to move beyond notions such as 'he made me do it' and rather allows an exploration of how structural, social and cultural context may impact such women's perceived offending 'choices' and behaviour. According to Madhok et al. (2013: 157) 'what matters most is not whether something is chosen, but what it is that is chosen and whether it is worthwhile and beneficial, or at least not detrimental, exploitative and destructive'. For the women in this study, although they all made a 'choice' to offend, they each argued that their 
offending 'choices' were at least in part influenced by their relationship with their male cooffender/partner and their broader social and structural positioning. This collectively highlights that when attempting to understand women co-offenders' experiences, the 'pre-occupation' with choice and rationality needs to be re-considered. Theorising and understanding should refocus to consider the role of emotions, centralising this in social context. This would enable a more nuanced understanding of the ways in which emotions influence such women's offending experiences, whilst recognising that varying levels of agency can co-exist in such circumstances.

Furthermore, when considering the extent of women co-offenders 'choices', the violence and injustices of the state and the ways in which these limit offending choices need to be better understood. As previously discussed, emotions such as fear and desperation were often exacerbated by punitive state responses or lack of support and recognition for experiences of victimization. The women co-offenders discussed here are not 'ideal victims' (Christie 1986) due to their participation in offending activity. Rather than their offending 'choices' being understood within the context of their abusive relationships, they were criminalised by criminal justice professionals and other state authorities, which further increased the harms they experienced. However, it is argued here that reducing experiences of victimisation and emotions such as fear to a potential offending 'risk factor' for such women is problematic. Although trauma informed, gender-responsive approaches to justice are increasingly acknowledging women's experiences of victimization, they do so by targeting individual women's potential 'risk', rather than acknowledging issues with institutional practices (Sharpe 2016). Such approaches focus on encouraging women to make better 'choices', which serves to responsibilise such women for their experiences of victimisation and ignores the role of the state in maintaining or exacerbating the harm they experience. It is argued here that the influence of emotions should be situated and understood within the context of punitive state practices, which criminalise and target marginalised women and consequently ignore or minimise their experiences of victimisation.

\section{Conclusion - moving forward}

Co-offending with a male, intimate partner often influences women's offending behaviours (Becker and McCorkel 2011) and potentially their pathways into crime (Barlow 2016), particularly if this relationship is abusive and violent. This chapter has examined the influence of emotions, such as fear and love, on women co-offenders offending behaviour and continued motivations to offend. In particular, the women in this study suggested that their abusive, toxic relationships with their male co-offender made them feel afraid to anger or disobey their partner, therefore limiting their perceived offending 'choices'. In the existing literature, there is minimal consideration of the influence of emotions on women's offending and when this is considered it is often understood as being the antithesis to 'rationality', thereby minimising such women's capacity for agency. Furthermore, experiences of love and fear are often dichotomised rather than understanding such emotions as a continuum (Jones 2008).

Feminist pathways literature has made important contributions to knowledge in understanding the ways in which women's social circumstance and experiences of victimisation can influence their offending behaviour (Belknap and Holsinger 2006; Daly 1994). However, experiences of victimisation for women offenders are increasingly identified as a 'risk factor' for future or continued offending, rather than developing a nuanced understanding of the ways in which emotions such as fear influence such women's lives. There needs to be a greater understanding of the complex interplay between micro-level (i.e. experiences of victimisation and abusive relationships) and macro-level (i.e. state harm, structural and social positioning) emotional influences and the ways in which these impact female co-offenders experiences and 'choices'. 
The ways in which such emotions influence women's offending decision-making needs to go beyond the individualised, 'risk' focussed approach currently dominating policy and practice and rather situate such women's choices within the context of broader state, institutional and structural harm. It is therefore argued here that the ways in which institutional and structural injustices further invoke fear and consequently harm for women offenders should be better understood.

\section{References}

Ballinger, Anette (2000). Dead Woman Walking. Aldershot: Ashgate.

Ballinger, Anette (2012). 'A Muted Voice from the Past: The "Silent Silencing" of Ruth Ellis’. Social and Legal Studies, 21: 445-467

Barlow, Charlotte (2016). Coercion and Women Co-Offenders: A Gendered Pathway into Crime. Bristol: Policy Press.

Barlow, Charlotte and Siobhan, Weare (2018). Women as Co-offenders: Pathways into Crime and Offending Motivations. Howard Journal of Criminal Justice, 58 (1): 86-103

Batchelor, Susan (2005). "Prove Me the Bam!": Victimization and Agency in the Lives of Young Women who Commit Violent Offences'. Probation Journal, 52(4): 358-375.

Becker, Sarah and Jill A. McCorkel (2011). 'The Gender of Criminal Opportunity: The Impact of Male Co-Offenders on Women's Crime'. Feminist Criminology, 6: 79-110.

Belknap, Joanne and Kristi Holsinger (2006). 'The Gendered Nature of Risk Factors for Delinquency'. Feminist Criminology, 1(1): 48-71.

Burman, Michelle and Susan Batchelor (2009). 'Between Two Stools? Responding to Young Women Who Offend'. Youth Justice, 9(3): 270-285.

Carlen, Pat (1988). Women, Crime and Poverty. Milton Keynes: Open University Press.

Carline, Anna (2005). 'Women Who Kill Their Abusive Partners: From Sameness to Gender Construction’. Liverpool Law Review, 26: 13-44.

Christie, Nils (1986). 'The Ideal Victim', in Ezzat A. Fattah (ed.), From Crime Policy to Victim Policy. Basingstoke: Macmillan.

Daly, Kathy (1994). Gender, Crime and Punishment. New Haven, CT: Yale University Press. de Haan, Willem and Ian Loader (2002). 'On the Emotions of Crime, Punishment and Social Control'. Theoretical Criminology, 6(3): 243-253.

Dobash, Rebecca and Russell Dobash (1979). Violence Against Wives: A Case Against the Patriarchy. New York: Free Press.

Fleetwood, Jennifer (2013). 'Keeping Out of Trouble: Female Crack Cocaine Dealers in England'. European Journal of Criminology, 11(1): 91-109.

Fleetwood, Jennifer (2015). 'A Narrative Approach to Women's Lawbreaking'. Feminist Criminology, 10(4): 368-388.

Gilligan, Catherine (1982). In a Different Voice. Cambridge, MA: Harvard University Press. 


\section{Verso header}

Harding, Sandra (1981). Feminism and Methodology: Social Science Issues. Bloomington: Indiana University Press.

Jones, Stephen (2008). 'Partners in Crime: A Study of the Relationship between Female Offenders and Their Co-Defendants'. Criminology and Criminal Justice, 8: 147-164.

Jones, Stephen (2011). 'Under Pressure: Women Who Plead Guilty to Crimes They Have Not Committed'. Criminology and Criminal Justice, 11: 77-90.

Kelly, Liz (2003). 'The Wrong Debate: Reflections on Why Force is Not the Key Issue with Respect to Trafficking in Women for Sexual Exploitation'. Feminist Review, 73: 139-144.

Klaver, Jessica R., Zina Lee and V. Gordon Rose (2008). 'Effects of Personality, Interrogation Techniques and Plausibility in an Experimental False Confession Paradigm'. Legal and Criminological Psychology, 13(1): 71-88

Koons-Witt, Barbara and Pamela Schram (2003). 'The Prevalence and Nature of Violent Offending by Females'. Journal of Criminal Justice, 31: 361-371.

Madhok, Sumi, Anne Phillips and Kalpana Wilson (2013). Gender, Agency and Coercion. London: Palgrave/Macmillan.

Maher, Lisa (1997). Sexed Work: Gender, Race and Resistance in a Brooklyn Drug Market. Oxford: Clarendon Press.

Mullins, Christoper and Richard Wright (2003). 'Gender Social Networks and Residential Burglary'. Criminology, 41: 813-840.

Richie, Beth E. (1996). Compelled to Crime: The Gender Entrapment of Battered Black Women. New York: Routledge.

Russett, Cynthia E. (1989). Sexual Science: The Victorian Construction of Womanhood. Cambridge, MA: Harvard University Press.

Schaffner, Auriel (2007). 'Violence Against Girls Provokes Girls' Violence: From Private Injury to Public Harm'. Violence Against Women, 13(12): 1229-1248.

Sharpe, Gilly (2016). 'Re-Imagining Justice for Girls: A New Agenda for Research'. Youth Justice, 16(1): 3-17.

Smith, Jonathan A. (2004). 'Reflecting on the Development of Interpretative Phenomenological Analysis and Its Contribution to Qualitative Research in Psychology'. Qualitative Research in Psychology, 1(3): 39-54.

Stark, Evan (2007). Coercive Control: How Men Entrap Women in Personal Life. London: Oxford University Press.

Sydie, Rosalind A. (1987). Natural Women, Cultured Men: A Feminist Perspective on Sociological Theory. Milton Keynes: Open University Press.

Walklate, Sandra (2001). Gender Crime and Criminal Justice. Devon: Willan Publishing.

Welle, Dorinda and Gregory Falkin (2000). 'The Everyday Policing of Women with Romantic Co-Defendants: An Ethnographic Perspective'. Women and Criminal Justice, 11: $45-65$. 
Recto header

Westmarland, Nicole (2015). Violence Against Women: Criminological Perspectives on Men's Violences. London: Routledge.

Yeo, Stanley (1993). 'Resolving Gender Bias in Criminal Defences'. Monash University Law Review, 19: 104-116. 